\title{
Voreloxin, a first-in-class anticancer quinolone derivative, acts synergistically with cytarabine in vitro and induces bone marrow aplasia in vivo
}

\author{
Caroline D. Scatena $\cdot$ Jeffrey L. Kumer · \\ Jennifer P. Arbitrario $\cdot$ Anthony R. Howlett . \\ Rachael E. Hawtin · Judith A. Fox · Jeffrey A. Silverman
}

Received: 18 September 2009 / Accepted: 24 December 2009 / Published online: 8 January 2010

(C) Springer-Verlag 2010

\begin{abstract}
Main purpose Voreloxin is a first-in-class anticancer quinolone derivative that intercalates DNA and inhibits topoisomerase II, inducing site-selective DNA damage. Voreloxin is in clinical studies, as a single agent and in combination with cytarabine, for the treatment of acute myeloid leukemia (AML). The preclinical studies reported here were performed to investigate the activity of voreloxin alone and in combination with cytarabine, in support of the clinical program.

Research questions Is single agent voreloxin active in preclinical models of AML? Does the combination of voreloxin and cytarabine enhance the activity of either agent alone?

Methods Inhibition of proliferation was studied in three cancer cell lines: HL-60 (acute promyelocytic leukemia), MV4-11 (AML), and CCRF-CEM (Acute lymphoblastic leukemia). Combination index (CI) analysis established the effect of the drugs in combination. A mouse model of bone marrow ablation was used to investigate in vivo efficacy of the drugs alone and in combination. Peripheral white blood cell and platelet counts were followed to assess marrow impact and recovery.
\end{abstract}

Authors have full control of all primary data and agree to allow the journal to review their data if requested.

C. D. Scatena - J. L. Kumer - J. P. Arbitrario - A. R. Howlett

R. E. Hawtin · J. A. Fox $(\square)$ · J. A. Silverman

Sunesis Pharmaceuticals, Inc.,

395 Oyster Point Blvd., South San Francisco,

CA 94080, USA

e-mail: jfox@ sunesis.com
Results Voreloxin and cytarabine alone and in combination exhibited cytotoxic activity in human leukemia cell lines and in vivo. The two drugs had additive or synergistic activity in vitro and supra-additive activity in vivo. Bone marrow ablation was accompanied by reductions in peripheral white blood cells and platelets that were reversible within 1 week, consistent with the AML treatment paradigm.

Conclusions These data support ongoing clinical evaluation of voreloxin both alone and in combination with cytarabine for the treatment of AML.

Keywords AML - Cytarabine - Voreloxin - Anthracycline . Topoisomerase II $\cdot$ Bone marrow ablation

\section{Introduction}

The standard treatment for newly diagnosed acute myeloid leukemia (AML) has not changed appreciably in the last few decades. Anthracyclines, along with the anthracenedione mitoxantrone, in combination with cytarabine, a nucleoside analog, remain the mainstays of treatment [28, 29]. Despite the efficacy of anthracycline-based therapies, patients with AML typically relapse and many fail to respond to their initial induction therapy [28, 29]. Therapy for relapsed AML is rarely curative, unless the patient undergoes an allogeneic bone marrow transplant (BMT), and most patients die from their disease [23, 28, 29]. Given that AML is primarily a disease of older patients, with a median age of diagnosis of 67 years, only a minority of patients will be eligible for BMT [30]. Clearly a need exists for alternative therapies for the treatment of this disease, including opportunities for bridging to the potentially curative option of hematopoietic stem cell transplant. 
Voreloxin is a first-in-class anticancer quinolone derivative that is currently in clinical studies as a single agent for the newly diagnosed elderly population, and in combination with cytarabine for relapsed/refractory AML. Voreloxin's mechanism of action is similar to that of the anthracyclines [4] in that it is a DNA damaging agent that intercalates DNA and poisons topoisomerase II [12]. However, because voreloxin is derived from a distinct chemical scaffold, both mechanistic and pharmaceutical features differentiate this new agent. The naphthyridine core, a member of the quinolone family, is less chemically reactive than that of the anthracyclines. The voreloxin-induced DNA damage, in contrast to anthracyclines, is site-selective, targeting GC rich regions similar to quinolone antibacterial drugs [12]. Voreloxin also has a favorable pharmacokinetic profile, with low clearance $\left(2 \mathrm{~L} / \mathrm{h} / \mathrm{m}^{2}\right)$, long terminal half-life $(22 \mathrm{~h})$, and dose-proportional exposure [1]. Voreloxin's $50 \mathrm{~L} / \mathrm{m}^{2}$ volume of distribution at steady state exceeds total body water, but is at least eightfold lower than that of the anthracycline daunomycin $[2,27]$. Taken together, the siteselective DNA damage and more limited distribution to normal tissues suggest a lower potential for the off-target organ toxicities common to the anthracyclines [15]. Thus far in clinical studies, the dose-limiting toxicities observed with voreloxin are reversible and include oral mucositis (leukemias) $[18,25]$ and neutropenia with an acceptable frequency of febrile neutropenia (solid tumors) [1].

Efficacy of the anthracyclines and mitoxantrone may be limited by sensitivity to the common tumor resistance mechanism of P-glycoprotein (P-gp) efflux, the expression of which is an independent prognostic factor for response to therapy in AML [7, 21, 24]. In contrast, voreloxin is not a P-gp substrate [8, 14], and activity has been reported in anthracycline-resistant preclinical models [14] and in patients with relapsed/refractory AML or platinum-resistant ovarian cancer for whom anthracycline-based therapies have failed [13]. The P-gp resistance mechanism is of particular relevance to AML, as both older and relapsed patients often express higher levels of this efflux pump [28].

Voreloxin is being evaluated for the treatment of AML. In order to support this clinical investigation, voreloxin was evaluated alone and in combination with cytarabine in vitro in human leukemia cell lines, and in vivo in a mouse model of bone marrow ablation and recovery.

\section{Materials and methods}

\section{Materials}

For in vitro cell viability assays, voreloxin was dissolved in $0.17 \%$ methanesulfonic acid (Sigma Chemical Co., St.
Louis, MO), forming a stock solution of $10 \mathrm{mM}$. The solution was stored at room temperature until it was diluted to working concentrations in fresh growth media. For vehicle-treated controls, an equivalent dilution of $0.17 \%$ methanesulfonic acid was added to growth media prior to addition to the cells. A stock solution of cytarabine (Cytosine $\beta$-D-arabinofuranoside $\mathrm{HCl}$, Sigma) was prepared in sterile water at $30 \mathrm{mM}$ and stored at $-20^{\circ} \mathrm{C}$ until it was diluted for use with fresh growth media. The clinical formulation of voreloxin $(10 \mathrm{mg} / \mathrm{ml})$ was used for in vivo studies and further diluted for injection into mice by dilution with vehicle $(0.17 \%$ methanesulfonic acid in $5 \%$ sorbitol (Sigma)). Cytarabine $(100 \mathrm{mg} / \mathrm{vial}$, Henry Schein, Inc., Melville, NY) was reconstituted in sterile water at $20 \mathrm{mg} / \mathrm{ml}$ and then diluted further if necessary for injection.

\section{Cell viability assays}

CCRF-CEM (acute lymphoblastic leukemia, ALL), MV411 (biphenotypic B myelomonocytic leukemia), and HL60 (acute promyelocytic leukemia) cell lines, obtained from the American Type Culture Collection (ATCC, Manassas, VA), were grown in RPMI- $1640+10 \%$ fetal bovine serum (FBS) at $37^{\circ} \mathrm{C}$ in a humidified atmosphere of $5 \% \mathrm{CO}_{2}$. Cells were seeded in opaque, clear bottom 96well plates at $1 \times 10^{5} /$ well in growth media. Voreloxin and/or cytarabine were serially diluted in growth media and added to the appropriate wells. Initial concentrations of voreloxin: CCRF-CEM, $1.5 \mu \mathrm{M}$; MV4-11, $1.0 \mu \mathrm{M}$; HL-60, $9 \mu \mathrm{M}$. Initial concentrations of cytarabine: CCRFCEM, $0.150 \mu \mathrm{M}$; MV4-11, $15 \mu \mathrm{M}$; HL-60, $9 \mu \mathrm{M}$. In the final well of the dilution series, media with vehicle were added to the cells. CellTiter-Glo Luminescent Cell Viability Assay (Promega, Madison, WI) was performed as per manufacturer's protocol, and the median of three replicate wells was used for $\mathrm{IC}_{50}$ curve generation. The $\mathrm{IC}_{50}$ values were determined in GraphPad/Prism (GraphPad Software, Inc., San Diego, CA) using non-linear regression of a sigmoidal dose response curve with a variable slope and no constraints. The effect of combining voreloxin and cytarabine was compared to the effect achieved with each drug alone. To provide information on the nature of the drug interaction, the combination index $(\mathrm{CI})$ [6] was calculated for two (CCRF-CEM, MV4-11) or three (HL-60) independent experiments according to the method of Zhao, et al. [31] The CI values were stratified as follows: $\mathrm{CI}>1.2$ the combination was antagonistic, $\mathrm{CI}$ from 1.2 to 0.85 the combination was additive, and for $\mathrm{CI}<0.85$ the combination was synergistic $[5,26]$. Voreloxin, combined with itself, was included as a control for additivity. 
Animals

CD-1 female mice (Charles River, Wilmington, MA) were acclimated for 3 days during which time their health was assessed daily. Purified water and food (PicoLab Rodent Diet 20, \#5053; Dean's Animal Feeds, San Carlos, CA) were provided ad libitum, and the animals were kept on a $12 \mathrm{~h}$ light and dark cycle. All experiments were performed in accordance with protocols approved by the Sunesis Pharmaceuticals, Inc. Institutional Animal Care and Use Committee and in accordance with local, state, and federal regulations.

\section{In vivo studies}

Animals were weighed, randomized by body weight, and assigned to the study groups before initiation of treatment. Voreloxin was administered intravenously (IV) at 10 or $20 \mathrm{mg} / \mathrm{kg}$ once on day zero and once on day four $(\mathrm{q} 4 \mathrm{~d} \times 2)$. Cytarabine was administered subcutaneously (SC) at 20 or $60 \mathrm{mg} / \mathrm{kg}$ every $8 \mathrm{~h}$ on day zero and day four $($ tid $q 4 d \times 2)$ [3]. Tissues and blood were sampled on days 6,8 , and 12 from at least three and not greater than ten animals per treatment group. Blood cell counts were performed at Quality Clinical Labs (SRI, Palo Alto, CA) on a Baker 9000 (Serono Baker Diagnostics, Allentown, PA) or ADVIA 120 (Bayer Diagnostics, Tarrytown, NY). Femurs were placed in Streck Tissue Fixative solution (Streck Laboratories, Omaha, NE), or in 10\% formalin solution (Richard-Allan Scientific, Kalamazoo, MI) for 24-48 h followed by a 70\% dehydrant (ethanol, isopropanol, methanol, Richard-Allan Scientific). Femurs were decalcified, paraffin embedded, and sectioned at Biopathology Labs (South San Francisco, CA). The four micron sections were stained with hematoxylin-eosin (H\&E) (Biopathology Labs). H\&E stained femurs were examined and percent cellularity of the bone marrow was determined. Digital photographs of representative femur sections were taken on a Leica DM2000 microscope (Leica Microsystems, Wetzlar, Germany) using Image-Pro Plus v6.1 software (Media Cybernetics, Silver Spring, MD).

\section{Statistical analysis}

For in vivo studies, the hematologic and histological results presented are the mean and standard error (SE) determined from each treatment group at the specified time points. Significant differences in percent bone marrow cellularity between treatment groups were determined using one-way ANOVA with $P \leq 0.05$ regarded as significant.

\section{Results}

Voreloxin has potent cytotoxic activity in human acute leukemia cell lines when used alone or in combination with cytarabine

The cytotoxic activities of voreloxin and cytarabine were evaluated in human acute leukemia cell lines MV4-11, HL60 , and CCRF-CEM. The average $\mathrm{IC}_{50}$ for voreloxin in the AML cell lines MV4-11 and HL-60 was $95 \pm 8 \mathrm{nM}$ and $884 \pm 114 \mathrm{nM}$, respectively. The ALL cell line, CCRF$\mathrm{CEM}$, was also sensitive to voreloxin with an average $\mathrm{IC}_{50}$ of $166 \pm 0.4 \mathrm{nM}$. Cytarabine was less potent than voreloxin in the AML cell line MV4-11 with an average $\mathrm{IC}_{50}$ of $1,457 \pm 127 \mathrm{nM}$. In HL-60 cells, the average $\mathrm{IC}_{50}$ was $689 \pm 245 \mathrm{nM}$, while in CCRF-CEM cells cytarabine was very active with an average $\mathrm{IC}_{50}$ of $15 \pm 5 \mathrm{nM}$.

The activity of voreloxin in combination with cytarabine was then assessed using drug concentrations extrapolated from individual $\mathrm{IC}_{50}$ values. When voreloxin and cytarabine were combined, the cytotoxic activity in MV411 and HL-60 cells was synergistic as demonstrated by a leftward shift in the voreloxin $\mathrm{IC}_{50}$ curves and calculated CIs less than 0.85 (Fig. 1a, b). In CCRF-CEM cells, combining voreloxin with cytarabine resulted in an additive increase in cytotoxicity with CIs of 0.85 (Fig. 1b) and 0.99 (Fig. 1a, b).

Voreloxin causes reversible bone marrow ablation alone or in combination with cytarabine

The activity of voreloxin was investigated in vivo by examining the effect of the drug in a mouse model of bone marrow ablation and recovery. CD-1 mice were administered vehicle, voreloxin, cytarabine, or a combination of voreloxin and cytarabine. Two days after completion of the treatment cycle (day 6), femurs were isolated, and bone marrow cellularity was assessed in hematoxylin-eosin (H\&E) stained sections. The mean bone marrow cellularity was $95 \%$ in the vehicle-treated animals indicating that the hematopoietic cells in the bone marrow were unaffected by the procedures, and the marrow was normal (Fig. 2a; c i). Administration of cytarabine at the maximum tolerated dose (MTD), $60 \mathrm{mg} / \mathrm{kg}$ tid q4d $\times 2$, caused a $26 \%$ reduction in bone marrow cellularity relative to vehicle by day six (Fig. 2a). In comparison, administration of voreloxin at MTD, $20 \mathrm{mg} / \mathrm{kg} \mathrm{q} 4 \mathrm{~d} \times 2$, resulted in an $80 \%$ reduction in cellularity relative to vehicle 2 days after treatment (Fig. 2a). In cytarabine-treated or voreloxin-treated animals, the percentage of hematopoietic cells in the marrow decreased in association with increased signs of marrow damage $[10,19]$ including dilation of sinusoids with 
(a)
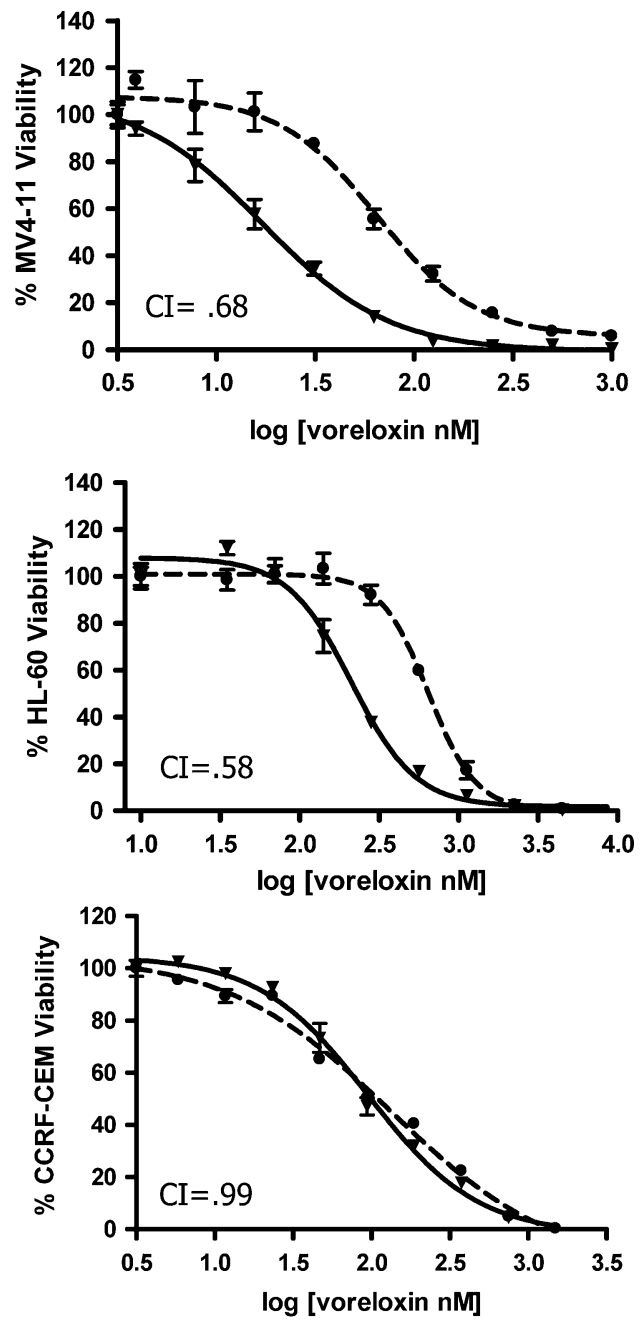

(b)

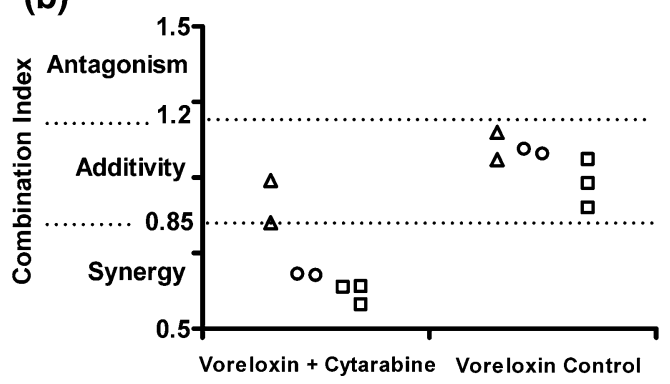

Fig. 1 Voreloxin combined with cytarabine has additive or synergistic activity in acute leukemia cell lines Viability studies were performed using human acute leukemia cell lines MV4-11, HL-60, and CCRF-CEM exposed for $72 \mathrm{~h}$ to serially diluted voreloxin and/or cytarabine. a Percent viability of cells treated with voreloxin alone or in combination: (Filled circle), voreloxin alone; (Filled inverted triangle), voreloxin combined with cytarabine. The combination index (CI) calculated from the curves is indicated and also shown graphically below. b Combination index $(\mathrm{CI})$ : $\mathrm{CI}<0.85$ indicates synergy, CI of $0.85-1.2$ indicates additivity, $\mathrm{CI}>1.2$ indicates antagonism. Each data point represents an independent experiment. (triangle), CCRF-CEM; (Circle), MV4-11; (Square), HL-60. Voreloxin control, voreloxin combined with itself infiltration of adipocytes and erythrocytes into the marrow stroma (Fig. 2c ii, iii).

For the combination study, CD-1 mice received cytarabine at $20 \mathrm{mg} / \mathrm{kg}$ tid on days zero and four, and voreloxin at $10 \mathrm{mg} / \mathrm{kg}$ on days zero and four. Cytarabine alone at $20 \mathrm{mg} / \mathrm{kg}$ (33\% MTD) had little effect on the bone marrow by day 6 while voreloxin alone at $10 \mathrm{mg} / \mathrm{kg}(50 \%$ MTD) reduced mean bone marrow cellularity relative to vehicle by $36 \%$ (Fig. 2 b, c, iv, v). In contrast, combining the two agents substantially enhanced the reduction in bone marrow cellularity; an $89 \%$ reduction relative to vehicle was observed when voreloxin (50\% MTD) was combined with the cytarabine (33\% MTD) (Fig. 2b, c, vi). There was a statistical difference in the cellularity of the bone marrow following the combination treatment when comparing to vehicle-treated animals $(P<0.001)$ and animals treated with cytarabine at MTD $(P<0.001)$. As seen with cytarabine and voreloxin alone, the combination treatment caused ablation of the marrow, dilation of sinusoids, and infiltration of adipocytes.

Concomitant reduction in peripheral lymphoid and myeloid cells occurred with decreased bone marrow cellularity

To determine whether the treatment-induced bone marrow ablation was reversible, repeat studies were extended to day 12 with the inclusion of peripheral blood counts along with bone marrow cellularity. CD-1 mice were treated with voreloxin, cytarabine, or the two drugs combined. In animals treated with voreloxin at $20 \mathrm{mg} / \mathrm{kg}$ on days zero and four (MTD), relative to vehicle-treated animals, bone marrow cellularity was reduced by $78 \%$ on day 6 , while in animals treated with cytarabine at $60 \mathrm{mg} / \mathrm{kg}$ tid on days zero and four (MTD) marrow cellularity decreased $42 \%$ (Fig. 3a). These decreases in cellularity were reversible for both agents with bone marrow returning to $100 \%$ cellularity by day 12 (Fig. 3a). The bone marrow in vehicle-treated animals was unaffected by treatment (Fig. 3a). Consistent with results of the experiment previously described in Fig. 2, when animals received the combination of voreloxin $(10 \mathrm{mg} / \mathrm{kg} \mathrm{q} 4 \mathrm{~d} \times 2)$ with cytarabine $(20 \mathrm{mg} / \mathrm{kg}$ tid $\mathrm{q} 4 \mathrm{~d} \times 2)$ bone marrow cellularity was reduced by $91 \%$ relative to vehicle on day 6 (Fig. 4a, D6). The marrow recovered from combination treatment with mean cellularity returning to $90 \%$ or greater 8 days after completing treatment (Fig. $4 a$, D12).

The integrity of the marrow within the vehicle-treated animals was reflected in peripheral blood counts with circulating neutrophils and lymphocytes counts within the normal range, $0.5-3 \times 10^{3} / \mu \mathrm{l}$ and $2-8 \times 10^{3} / \mu 1$, [9], respectively (Fig. 3b, days 6-12). A decrease in platelet 

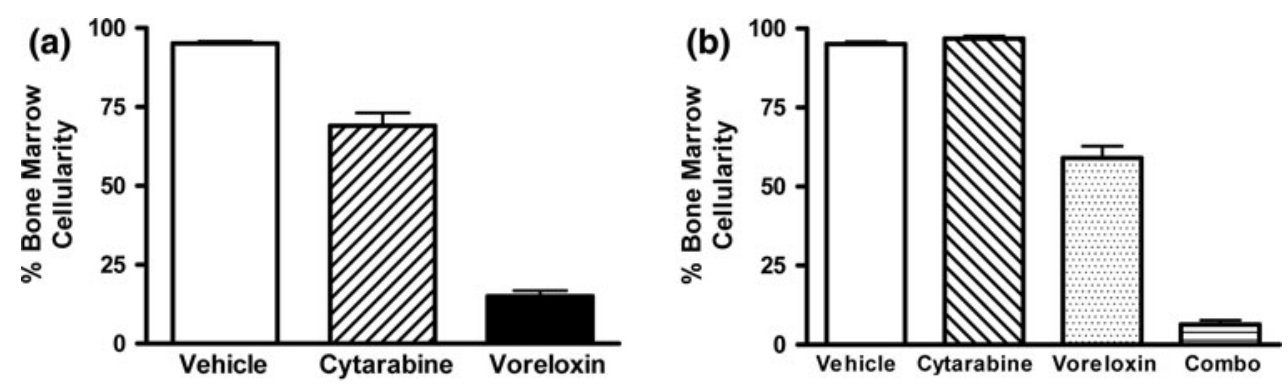

(b)

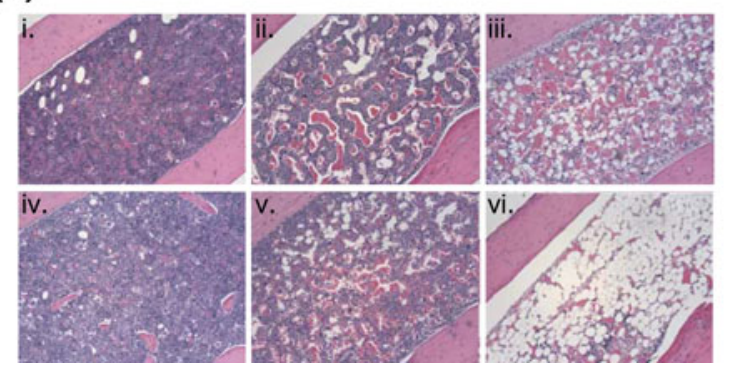

Fig. 2 Voreloxin and cytarabine, alone or in combination, ablate normal bone marrow CD-1 mice received vehicle, voreloxin, cytarabine, or voreloxin and cytarabine in combination on day 0 and 4 . On day 6 , femurs were isolated, and cellularity was assessed in $\mathrm{H} \& \mathrm{E}$ stained bone marrow sections. a Percent cellularity remaining in the bone marrow following treatment: Vehicle, $0.17 \%$ methanesulfonic acid in 5\% sorbitol IV q4d $\times 2$ and water SC tid q $4 \mathrm{~d} \times 2$; Cytarabine, $60 \mathrm{mg} / \mathrm{kg} \mathrm{SC}$ tid q4d $\times 2$; Voreloxin, $20 \mathrm{mg} / \mathrm{kg}$ IV q4d $\times 2$. b Percent cellularity remaining in the bone marrow following treatment: Vehicle, as in (a); Cytarabine, $20 \mathrm{mg} / \mathrm{kg} \mathrm{SC}$ tid q $4 \mathrm{~d} \times 2$; Voreloxin, $10 \mathrm{mg} / \mathrm{kg}$ IV q $4 \mathrm{~d} \times 2$; Combo, cytarabine, $20 \mathrm{mg} / \mathrm{kg} \mathrm{SC}$ tid q $4 \mathrm{~d} \times 2$ and voreloxin, $10 \mathrm{mg} / \mathrm{kg}$ IV $\mathrm{q} 4 \mathrm{~d} \times 2$. c $\mathrm{H} \& \mathrm{E}$ stained femur sections, original magnification $\times 100$ : i. vehicle, as in (a); ii. cytarabine, $60 \mathrm{mg} / \mathrm{kg} \mathrm{SC}$ tid q $4 \mathrm{~d} \times 2$; iii. voreloxin, $20 \mathrm{mg} / \mathrm{kg}$ IV q4d $\times 2$; iv. cytarabine, $20 \mathrm{mg} / \mathrm{kg} \mathrm{SC}$ tid q4d $\times 2$; v. voreloxin, $10 \mathrm{mg} / \mathrm{kg}$ IV q $4 \mathrm{~d} \times 2$; vi. combo: cytarabine, $20 \mathrm{mg}$ / $\mathrm{kg}$ SC tid $\mathrm{q} 4 \mathrm{~d} \times 2$, and voreloxin, $10 \mathrm{mg} / \mathrm{kg}$ IV q $4 \mathrm{~d} \times 2$

or $10 \mathrm{mg} / \mathrm{kg}$ voreloxin failed to reduce peripheral neutrophils below the normal range of $0.5-3 \times 10^{3} / \mu 1$ [9] (Fig. 4b). The circulating neutrophils in combination treated mice returned (mean $2.6 \times 10^{3} / \mu \mathrm{l}$ ) to normal by day 12 reflecting the recovery of the bone marrow (Fig. 4b). Circulating lymphocytes showed a threefold decrease at the nadir on day 8 although these levels still fell within the anticipated normal range of $2-8 \times 10^{3} / \mu \mathrm{l}$ (Fig. 4b). Circulating platelets in the combination treated mice were below normal through day 8 but rebounded to acceptable levels by day 12 .

\section{Discussion}

Treatment of acute myeloid leukemia with cytarabine in combination with an anthracycline has been the standard of care for 30 years [28, 29]. Although initial responses to this therapy are observed, some patients are refractory and most will ultimately relapse [28, 29]. Here, we report preclinical studies of voreloxin, a novel agent currently being explored in the clinic as a potential AML therapy, both as a single agent and in combination with cytarabine. The mechanism of action of voreloxin bears some similarities with the anthracyclines, which therefore identify indications where voreloxin may be active clinically. In addition, key elements of $0.03 \times 10^{3} / \mu \mathrm{l}$ at the nadir on day 8 (Fig. $4 \mathrm{~b}$ ). By comparison, treatment of animals with vehicle, $20 \mathrm{mg} / \mathrm{kg}$ cytarabine 
Fig. 3 Voreloxin or cytarabine at MTD causes a reversible decrease in myeloid and lymphoid cells in bone marrow and peripheral blood CD-1 mice received vehicle, voreloxin, or cytarabine on day 0 and 4 . a Percent cellularity remaining in the bone marrow on days 6 (D6) and 12 (D12): Vehicle, $0.17 \%$ methanesulfonic acid in $5 \%$ sorbitol IV q4d $\times 2$ and water $\mathrm{SC}$ tid q4d $\times 2$; Cytarabine, $60 \mathrm{mg} / \mathrm{kg} \mathrm{SC}$ tid q $4 \mathrm{~d}$ $\times 2$; Voreloxin, $20 \mathrm{mg} / \mathrm{kg} \mathrm{IV} \mathrm{q} 4 \mathrm{~d}$ $\times 2$. b Peripheral blood was isolated on days 6,8 , and 12 for analysis. Neutrophils, lymphocytes, and platelets in circulation $\left(\times 10^{3} / \mu \mathrm{l}\right)$ following treatment: (Filled square), vehicle; (Filled triangle), cytarabine, $60 \mathrm{mg} / \mathrm{kg} \mathrm{SC}$ tid q $4 \mathrm{~d}$ $\times 2$; (Filled circle), voreloxin, $20 \mathrm{mg} / \mathrm{kg}$ IV q4d $\times 2$. Black arrow represents the three cytarbine doses, and the gray arrow represents the voreloxin dose

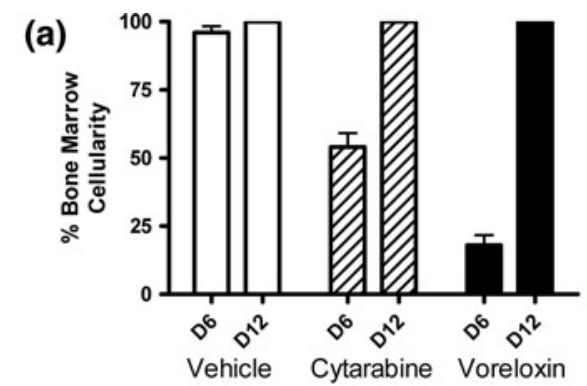

(b)
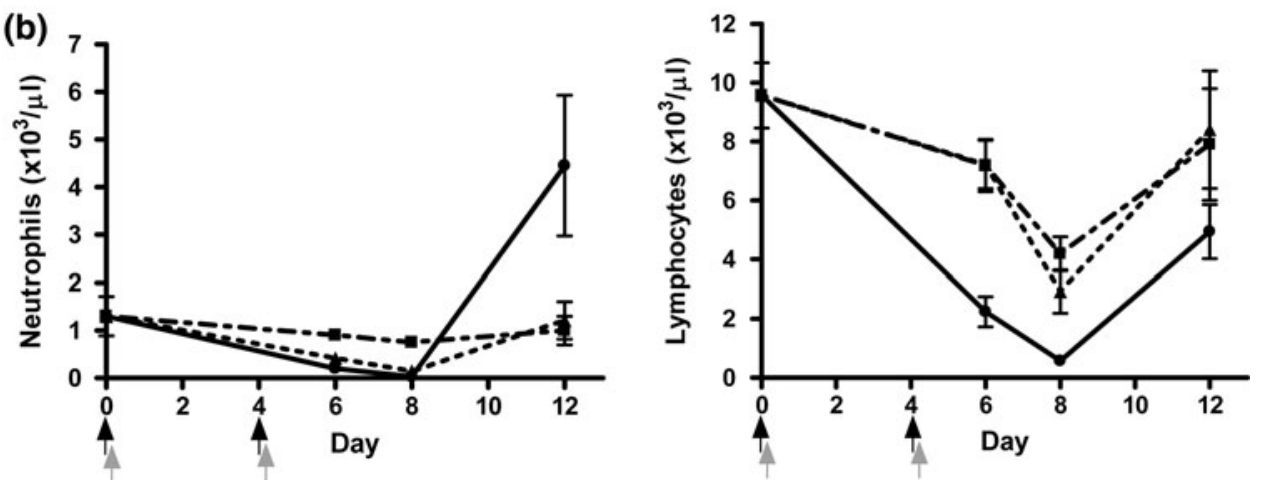

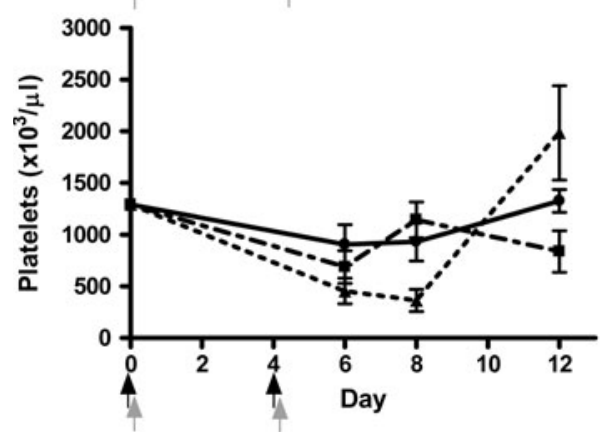

structural, mechanistic, and pharmacologic differentiation suggest that voreloxin represents an evolutionary step in the development of topoisomerase II inhibitors. Voreloxin is a first-in-class anticancer quinolone analog, that intercalates DNA and inhibits topoisomerase II, inducing site-selective DNA double-strand breaks [12]. The drug is cytotoxic to tumor cells in vitro and has potent antitumor activity in numerous human xenograft and murine syngeneic tumor models of diverse tissue origin [14]. These models included both solid and hematologic tumor cell lines among which several were multidrug resistant [14]. Voreloxin has favorable pharmacologic properties relative to the anthracyclines $[2,21,24,27]$, given that it is not a P-glycoprotein substrate [8, 14], undergoes minimal cytochrome P450 and UDP glucuronosyltransferase (UGT)-mediated metabolism in vivo [8], and has low potential for cytochrome P450-mediated drug-drug interactions.

Nanomolar concentrations of voreloxin decreased viability of acute leukemia cell lines by $50 \%$ in vitro. The AML cell line MV4-11, which is resistant to cytarabine in vitro, was sensitive to voreloxin treatment. MV4-11 cells harbor the FLT3 internal tandem duplication (ITD) mutation [20], and AML patients with this mutation have a relatively poorer prognosis [11]. The sensitivity of MV4-11 cells to voreloxin suggests that it may be an effective treatment for AML patients with the ITD mutation.

The combination index method (CI) [6] was used to assess the activity of voreloxin combined with cytarabine in acute leukemia cell lines. Combining voreloxin and cytarabine resulted in synergistic activity in the myeloid leukemia cell lines MV4-11 and HL-60, but only additive activity was achieved in CCRF-CEM acute lymphoid leukemia cells, which are highly sensitive to single agent cytarabine. The synergistic activity in two leukemia cell lines with voreloxin combined with cytarabine supported further exploration of this combination in animal models.

Bone marrow cellularity was measured in femurs of voreloxin-treated mice as a surrogate measurement for the activity of voreloxin as a treatment for acute leukemias. Administering voreloxin to normal mice at the MTD reduced bone marrow cellularity by as much as $80 \%$, whereas cytarabine at the MTD reduced bone marrow 
Fig. 4 Voreloxin and cytarabine in combination causes reversible neutropenia with a more modest impact on platelets CD-1 mice received vehicle, voreloxin, cytarabine, or voreloxin and cytarabine in combination on day 0 and 4 . a Percent cellularity remaining in the bone marrow on days 6 (D6) and 12 (D12): Vehicle, $0.17 \%$ methanesulfonic acid in 5\% sorbitol IV $\mathrm{q} 4 \mathrm{~d} \times 2$ and water SC tid q4d $\times 2$; Cytarabine, $20 \mathrm{mg} / \mathrm{kg} \mathrm{SC}$ tid q4d $\times 2$; Voreloxin, $10 \mathrm{mg} / \mathrm{kg}$ IV q $4 \mathrm{~d} \times 2$; Combo, cytarabine, $20 \mathrm{mg} / \mathrm{kg}$ SC tid q $4 \mathrm{~d} \times 2$, and voreloxin, $10 \mathrm{mg} / \mathrm{kg}$ IV q $4 \mathrm{~d} \times 2$. b Peripheral blood was isolated on days 6, 8, and 12 for analysis. Absolute neutrophils, absolute lymphocytes, and platelets $\left(\times 10^{3} / \mu \mathrm{l}\right)$ in circulation following treatment: (Filled square), vehicle; (Triangle), cytarabine, $20 \mathrm{mg} / \mathrm{kg}$ SC tid q4d $\times 2$; (Circle), voreloxin, $10 \mathrm{mg} / \mathrm{kg} \mathrm{IV}$ $\mathrm{q} 4 \mathrm{~d} \times 2 ;$ (Filled inverted triangle), combo: cytarabine, $20 \mathrm{mg} / \mathrm{kg} \mathrm{SC}$ tid q $4 \mathrm{~d} \times 2$, and voreloxin, $10 \mathrm{mg} / \mathrm{kg} \mathrm{IV} \mathrm{q4d} \times 2$. Black arrow represents the three cytarbine doses, and the gray arrow represents the voreloxin dose
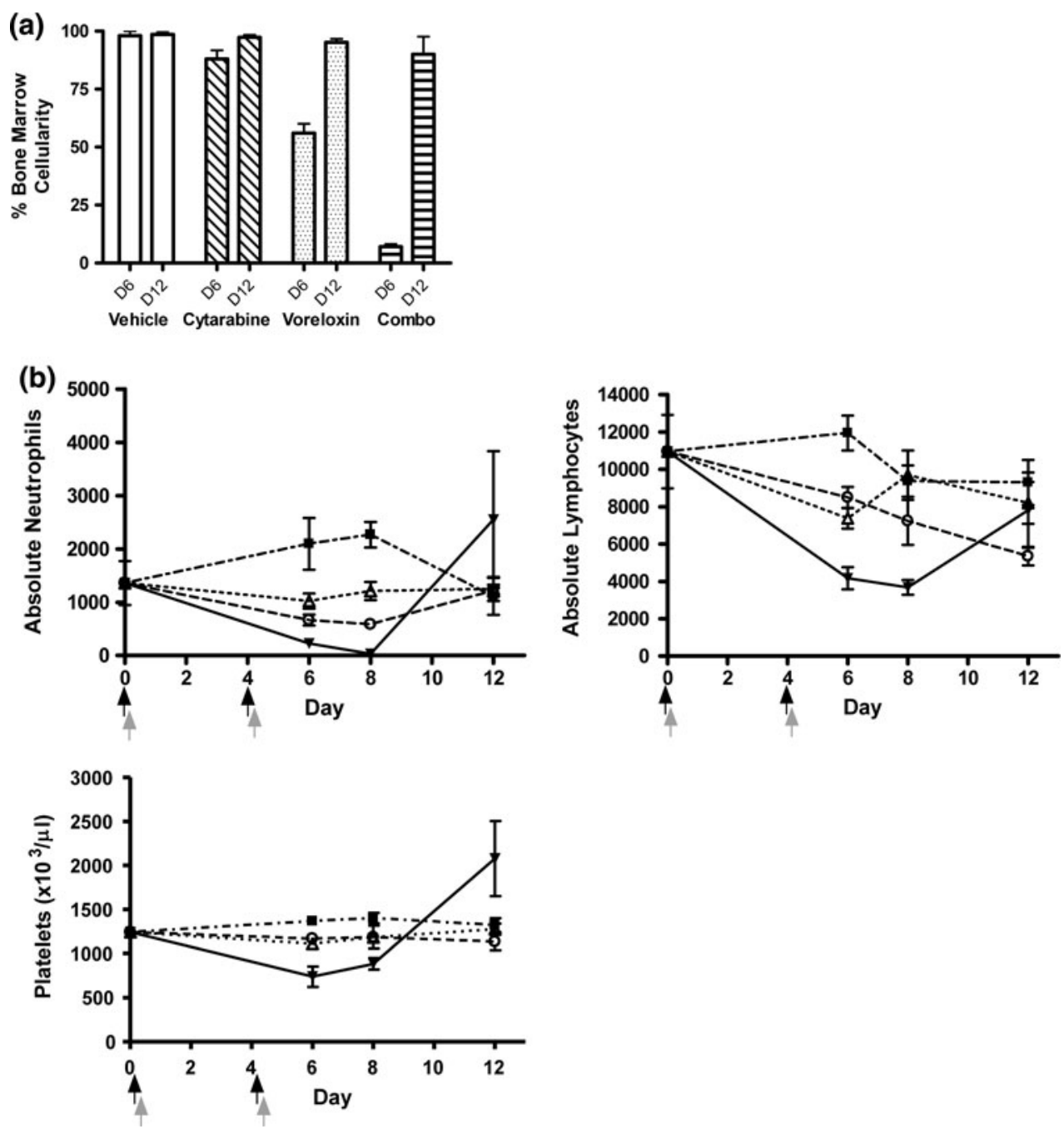

cellularity by as much as $42 \%$. The ablation of the bone marrow in the voreloxin-treated animals was reversible, with cellularity returning to $100 \% 1$ week post-treatment, identical to the recovery time observed in cytarabinetreated animals. When voreloxin (50\% MTD) was combined with cytarabine (33\% MTD), there was a dramatic $91 \%$ reduction in bone marrow cellularity, which returned to normal within 1 week. Following voreloxin treatment alone or in combination with cytarabine, peripheral neutrophils, lymphocytes, and platelets decreased in the animals but returned to normal levels 1 week later, reflecting the recovery of hematopoiesis. The combination dose approximates the MTD for co-administration of the agents; decreasing the voreloxin concentration impaired the bone marrow ablation, and an increase in either agent was associated with increased toxicity without significant gain in efficacy.

Cytarabine derives its cytotoxic activity by inhibiting DNA polymerase, [22, 33] DNA ligase [32] and by its direct incorporation into DNA, leading to termination of synthesis and generation of DNA strand breaks [16, 17].
A possible explanation for the enhanced activity of the combination of voreloxin and cytarabine is that cells exit S-phase and enter G2 with cytarabine-induced DNA damage. Upon G2 entry, voreloxin induces additional DNA damage in the form of double-strand breaks stimulating cell death. In addition, cells that sustain voreloxin-induced DNA double-strand breaks may suffer from an impaired ability to repair these breaks due to the cytarabine-induced DNA synthesis blockade. The mechanistic basis for the enhanced activity observed when both agents are combined is under investigation.

The ability of voreloxin to induce a reversible bone marrow ablation equivalent to or better than cytarabine alone supports the clinical investigation of voreloxin in AML. Current clinical trials in AML include a phase II study with single agent voreloxin in newly diagnosed elderly patients and a phase Ib/II study with voreloxin in combination with cytarabine in relapsed or refractory patients. In both studies to date, complete remissions with or without platelet recovery have been reported in voreloxin-treated patients 
[18, 25] demonstrating the antileukemic activity of voreloxin and its potential as a new treatment for AML.

Acknowledgments The authors would like to thank Dr. Carl L. Millward and Dr. Lisa H. Tai for pathology review, Aaron McCarty and his staff for animal husbandry support.

Conflict of interest statement All authors are current or former employees of Sunesis Pharmaceuticals. The research was funded by Sunesis Pharmaceuticals.

\section{References}

1. Advani RH, Hurwitz HI, Gordon MS, Ebbinghaus SW, Mendelson DS, Wakelee HA, Hoch U, Silverman JA, Havrilla NA, Berman CJ, Fox JA, Allen RS, DC A (2009) Phase 1 Experience with Voreloxin, a First in Class Anticancer Quinolone Derivative, in Relapsed/Refractory Solid Tumors: A report on two dosing schedules (Submitted)

2. Alberts DS, Bachur NR, Holtzman JL (1971) The pharmacokinetics of daunomycin in man. Clin Pharmacol Ther 12:96-104

3. Burke PJ, Karp JE, Vaughan WP (1981) Chemotherapy of leukemia in mice, rats, and humans relating time of humoral stimulation, tumor growth, and clinical response. J Natl Cancer Inst 67:529-538

4. Capranico G, De Isabella P, Penco S, Tinelli S, Zunino F (1989) Role of DNA breakage in cytotoxicity of doxorubicin, 9-deoxydoxorubicin, and 4-demethyl-6-deoxydoxorubicin in Murine Leukemia P388 cells. Cancer Res 49:2022-2027

5. Chou TC (2006) Theoretical basis, experimental design, and computerized simulation of synergism and antagonism in drug combination studies. Pharmacol Rev 58:621-681

6. Chou TC, Talaly P (1977) A simple generalized equation for the analysis of multiple inhibitions of Michaelis-Menten kinetic systems. J Biol Chem 252:6438-6442

7. Del Poeta G, Stasi R, Aronica G, Venditti A, Cox M, Bruno A, Buccisano F, Masi M, Tribalto M, Amadori S, Papa G (1996) Clinical relevance of P-glycoprotein expression in de novo acute myeloid leukemia. Blood 87:1997-2004

8. Evanchik MJ, Allen D, Yoburn JC, Silverman JA, Hoch U (2009) Metabolism of (+)-1, 4-dihydro-7-(trans-3-methoxy-4-methylamino-1-pyrrolidinyl)-4-oxo-1-(2-thiazolyl)-1, 8-naphthyridine3-carboxylic acid (voreloxin; formerly SNS-595), a novel replication-dependent DNA-damaging agent. Drug Metab Dispos 37:594-601

9. Everds N (2004) Hematology of the Mouse. In: Hedrich H (ed) The Laboratory Mouse. Elsevier Academic Press, Amsterdam

10. Fliedner TM, Graessle D, Paulsen C, Reimers K (2002) Structure and function of bone marrow hemopoiesis: mechanisms of response to ionizing radiation exposure. Cancer Biother Radiopharm 17:405-426

11. Gilliland DG, Griffin JD (2002) The roles of FLT3 in hematopoiesis and leukemia. Blood 100:1532-1542

12. Hawtin RE, Stockett DE, Byl JA, McDowell RS, Tan N, Arkin MR, Wang W, Conroy A, Osheroff N, J.A. F (2009) Voreloxin is an anticancer quinolone derivative that intercalates DNA and poisons topoisomerase II

13. Hirte H, McGuire W, Edwards R, Husain A, Hoskins P, Michels J, Matulonis U, Sexton C, Mahadocon K, Fox J, Michelson G (2009) A phase 2 trial of voreloxin in women with platinum-resistant ovarian cancer. In: Proceedings, American Society of Clinical Oncology (ASCO) annual meeting

14. Hoch U, Lynch J, Sato Y, Kashimoto S, Kajikawa F, Furutani Y, Silverman J (2009) Voreloxin, formerly SNS-595, has potent activity against a broad panel of cancer cell lines and in vivo tumor models. Cancer Chemother Pharmacol 64:53-65
15. Jaenke RS, Deprez-DeCampeneere D, Trouet A (1980) Cardiotoxicity and comparative pharmacokinetics of six anthracyclines in the rabbit. Cancer Res 40:3530-3536

16. Kufe DW, Major PP, Egan EM, Beardsley GP (1980) Correlation of cytotoxicity with incorporation of ara-C into DNA. J Biol Chem 255:8997-9000

17. Kufe DW, Munroe D, Herrick D, Egan E, Spriggs D (1984) Effects of 1-beta-D-arabinofuranosylcytosine incorporation on eukaryotic DNA template function. Mol Pharmacol 26:128-134

18. Lancet J (2009) Phase Ib/II pharmacokinetic/pharmacodynamic (PK/PD) study of combination voreloxin and cytarabine in relapsed or refractory AML patients. In: Proceedings, American Society of Clinical Oncology (ASCO) annual meeting

19. Lapidot T, Dar A, Kollet O (2005) How do stem cells find their way home? Blood 106:1901-1910

20. Levis M, Pham R, Smith BD, Small D (2004) In vitro studies of a FLT3 inhibitor combined with chemotherapy: sequence of administration is important to achieve synergistic cytotoxic effects. Blood 104:1145-1150

21. List AF (1996) Role of multidrug resistance and its pharmacological modulation in acute myeloid leukemia. Leukemia 10:937-942

22. Matsukage A, Ono K, Ohashi A, Takahashi T, Nakayama C, Saneyoshi M (1978) Inhibitory effect of 1-beta-D-arabinofuranosylthymine 5'-triphosphate and 1-beta-D-arabinofuranosylcytosine 5'-triphosphate on DNA polymerases from murine cells and oncornavirus. Cancer Res 38:3076-3079

23. Moore J, Nivison-Smith I, Goh K, Ma D, Bradstock K, Szer J, Durrant S, Schwarer A, Bardy P, Herrmann R, Dodds A (2007) Equivalent survival for sibling and unrelated donor allogeneic stem cell transplantation for acute myelogenous leukemia. Biol Blood Marrow Transplant 13:601-607

24. Nielsen D, Maare C, Skovsgaard T (1996) Cellular resistance to anthracyclines. Gen Pharmacol 27:251-255

25. Ravandi F, Stuart R, Maris M, Stone R, Cripe R, Cooper M, Strickland S, Turturro F, Stock W, Mahadocon K, Fox J, Michelson G, Berman C (2009) A phase II study of voreloxin as single agent therapy for elderly patients (pts) with newly diagnosed acute myeloid leukemia (AML). American Society of Clinical Oncology (ASCO) Annual Meeting

26. Reynolds CP, Maurer BJ (2005) Evaluating response to antineoplastic drug combinations in tissue culture models. Methods Mol Med 110:173-183

27. Speth PA, Linssen PC, Boezeman JB, Wessels HM, Haanen C (1987) Leukemic cell and plasma daunomycin concentrations after bolus injection and $72 \mathrm{~h}$ infusion. Cancer Chemother Pharmacol 20:311-315

28. Stone RM, O’Donnell MR, Sekeres MA (2004) Acute Myeloid Leukemia: ASH education Hematology: 98-117

29. Tallman MS, Gilliland DG, Rowe JM (2005) Drug therapy for acute myeloid leukemia. Blood 106:1154-1163

30. Wong R, Giralt SA, Martin T, Couriel DR, Anagnostopoulos A, Hosing C, Andersson BS, Cano P, Shahjahan M, Ippoliti C, Estey EH, McMannis J, Gajewski JL, Champlin RE, de Lima M (2003) Reduced-intensity conditioning for unrelated donor hematopoietic stem cell transplantation as treatment for myeloid malignancies in patients older than 55 years. Blood 102:3052-3059

31. Zhao L, Wientjes MG, Au JL (2004) Evaluation of combination chemotherapy: integration of nonlinear regression, curve shift, isobologram, and combination index analyses. Clin Cancer Res 10:7994-8004

32. Zittoun J, Marquet J, David JC (1991) Mechanism of inhibition of DNA ligase in Ara-C treated cells. Leuk Res 15:157-164

33. Zittoun J, Marquet J, David JC, Maniey D, Zittoun R (1989) A study of the mechanisms of cytotoxicity of Ara-C on three human leukemic cell lines. Cancer Chemother Pharmacol 24:251255 